Revista

ACor das Letras
Revista Digital dos Programas de Pós-Graduação do Departamento de Letras e Artes da UEFS

Feira de Santana, v. 19, n. Especial, p. 23-39, março de 2018

http://periodicos.uefs.br/index.php/acordasletras/index

d) http://dx.doi.org/10.13102/cl.v19i4\%20Especial.2857

\title{
O PEPP e os estudos sobre o português de Salvador
}

\author{
The PEPP and the studies of Portuguese spoken in Salvador
}

\author{
Norma da Silva Lopes* \\ Universidade do Estado da Babia \\ Salvador, Bahia, Brasil
}

Resumo: Este artigo trata do acervo de fala intitulado Programa de Estudos sobre o Português Popular de Salvador, o PEPP (LOPES; SOUZA; SOUZA, 2009), muito utilizado por pesquisadores baianos, para o estudo do português de Salvador. O referido acervo foi constituído de início para servir de corpus para três teses de doutorado, na época em realização na Universidade Federal da Bahia. O PEPP se guiou pelas orientações de entrevista sociolinguística (LABOV, 2008[1972]). Esse texto objetiva, primeiramente, (1) apresentar os fundamentos teóricos do acervo PEPP já constituído, o PEPP 1; (2) caracterizar o PEPP 1, seus objetivos e pesquisadores responsáveis; (3) expor dados sobre sua composição: número de faixas etárias, escolaridades e gêneros, metodologia das entrevistas, etc; (4) listar alguns estudos com base nos dados do PEPP e (5) discutir a importância e representativa do PEPP no contexto dos estudos sociolinguísticos na Bahia. No presente momento, o PEPP 2 está em fase de planejamento, duas décadas depois, buscando colocar à disposição um novo acervo que dê margem a estudos em duas sincronias em análises sociolinguísticas diversas. Além da caracterização do PEPP 1, este artigo pretende apresentar o que se planeja como PEPP 2 e como esse acervo deve se caracterizar. Dessa forma, este texto objetiva colocar a proposta do PEPP 2 em discussão/apreciação pela comunidade científica da área, para possibilitar sugestões para que o PEPP possa dar sua contribuição para os estudos atuais sobre o português brasileiro.

Palavras-chave: Programa de Estudos sobre o Português Popular de Salvador. Pesquisas linguísticas na Bahia. Português brasileiro. Acervo.

\begin{abstract}
This article deals with the speech collection entitled "Program of Studies on the Popular Portuguese of Salvador", the PEPP (SOUZA; SOUZA, 2009), widely used by Bahian researchers, for the study of Salvadoran Portuguese. This collection was initially constituted to serve as corpus for three doctoral theses, at the time being held at the Federal University of Bahia. The PEPP was guided by the sociolinguistic interview guidelines (LABOV, 2008 [1972]). This text aims, first, to (1) present the theoretical foundations of the PEPP already constituted, the PEPP 1; (2) characterize PEPP 1, its objectives and responsible researchers; (3) to present data about their composition: number of age groups, schooling and gender, interview methodology; (4) to list some studies based on PEPP data and (5) to discuss the importance and representativeness of PEPP in the context of sociolinguistic studies in Bahia. At present, PEPP 2 is in the planning phase two decades later, aiming to make available a new collection that allows for studies in two synchronies in diverse sociolinguistic analyzes. In addition to the characterization of PEPP 1, this article intends to present what is planned as PEPP 2 and how this collection should be characterized. Thus, this text aims to put the PEPP 2 proposal under discussion / appreciation by the scientific community in the area, to enable suggestions for PEPP to contribute to current studies on Brazilian Portuguese.
\end{abstract}

Keywords: Program of Studies on the Popular Portuguese of Salvador. Linguistic research in Bahia. Brazilian portuguese. Collection.

** Doutora em Letras e Linguística (UFBA), professora da Universidade do Estado da Bahia (UNEB), Salvador/BA. E-mail: nlopes58@gmail.com 


\section{INTRODUÇÃO}

Este texto objetiva tratar do acervo Programa de Estudos sobre o Português Popular de Salvador (PEPP), constituído entre os anos de 1998 e 2000, o PEPP 1 (LOPES; SOUZA; SOUZA, 2009), sua importância como objeto de observação da fala de Salvador e do PEPP 2, ainda em planejamento, com a observação em outra sincronia, o que possibilitará estudos da mudança em tempo real. O PEPP surgiu para preencher uma necessidade de amostras da fala de pessoas com pouca ou média escolarização em Salvador, e se guiou pelas orientações de entrevista sociolinguística (LABOV, 2008 [1972]).

Existe uma necessidade constante de que se registrem usos da língua de épocas diferentes, que possibilitem não só estudos da variação nas diversas sincronias, o que dá margem para que se promova o estudo, não só da variação, mas também da mudança linguística. O PEPP se destinou a não só fazer registros da língua de uso real da fala de Salvador na época de sua constituição, mas também promover pesquisas linguísticas em diversos níveis no estado da Bahia, dando, assim, sua contribuição para o entendimento do português brasileiro.

Este texto organiza-se da seguinte forma: $\mathrm{Na}$ seção 1, serão apresentados os pressupostos teórico-metodológicos que embasam a constituição do PEPP e do PEPP2. Em 2, faz-se o percurso histórico do programa; a seção 3 trata da estratificação do acervo e dos critérios da formatação dos questionários e das transcrições; em 4, discute-se a importância do PEPP nos estudos sobre o português falado na Bahia; em 5, listam-se, com curtos comentários, alguns trabalhos realizados com o acervo tratado neste texto; em 6, apresentam-se propostas iniciais para o PEPP 2 e, finalmente, em 7, encerra-se o texto com algumas considerações.

\section{BASES TEÓRICO-METODOLÓGICAS}

A pesquisa sociolinguística busca, conforme as orientações labovianas (LABOV, 2008[1972]), estuda a variação linguística, comum a todas as línguas, e mostrar que ela não é aleatória, relacionando-a a questões estruturais e sociais; e mostrar a sua importância desse estudo para o entendimento da mudança linguística. Através dos estudos variacionistas, a mudança linguística pode ser captada no seu curso, através da observação da competição entre as variantes.

A sociolinguística laboviana parte de dois conceitos básicos: o vernáculo e a comunidade de fala. Entende-se o vernáculo como a variedade descomprometida do falante, quando não há preocupação no como ele está usando a língua. O vernáculo se mostra com frequência em conversas familiares, encontro de amigos próximos, por exemplo. Pode-se captar também o vernáculo em narrativas de fatos marcantes da vida do falante, quando o assunto o leva a não se preocupar com o que está a sua volta. Diante disso, as entrevistas que buscam captar o vernáculo devem estimular esse tipo de narrativas. Para que os acervos captem o vernáculo, há necessidade de que as entrevistas sociolinguísticas provoquem o surgimento dessa fala descomprometida, e as narrativas 
foram, na constituição do PEPP, o caminho que se buscou, para minimizar o paradoxo do observador.

Ao tratar de comunidade de fala, os estudos sociolinguísticos remetem, não a grupos que falam da mesma forma. Guy (2000) define comunidade de fala como

-características linguísticas compartilhadas; isto é, palavras, sons ou construções gramaticais que são usados na comunidade, mas não o são fora dela.

- densidade de comunicação interna relativamente alta; isto é, as pessoas normalmente falam com mais frequência com outras que estão dentro do grupo do que com aquelas que estão fora dele.

- normas compartilhadas; isto é, atitudes em comum sobre o uso da língua, normas em comum sobre a direção da variação estilística, avaliações sociais em comum sobre variáveis linguísticas. (GUY, 2000, p. 1-2)

Como esse pesquisador conceitua a comunidade, não é a homogeneidade linguística que caracteriza a comunidade linguística, mas, sim, principalmente semelhanças na avaliação que os falantes fazem dos usos da língua, na frequência com que eles se comunicam entre si e nos traços linguísticos que opõem essa comunidade às demais.

1) As entrevistas sociolinguísticas que compõem o PEPP buscam captar o vernáculo em uma comunidade de fala, composta pela população não universitária de Salvador.

\section{O SURGIMENTO DO PEPP}

A fala de Salvador foi estudada desde os anos setenta em diversas dissertações, teses e outros trabalhos, utilizando-se como corpus o material recolhido pelo Projeto Norma Urbana Culta de Salvador (NURC/SSA), que busca o estudo do português falado por pessoas com nível universitário. Sentiu-se, desde que esse material passou a ser utilizado, uma lacuna quanto à possibilidade de estudo de uma amostra com outros níveis de escolaridade. A necessidade de amostras atualizadas do português falado em Salvador levou, em 1998, à constituição desse programa, que só foi possível por tomar como ponto de partida a experiência do grupo envolvido nas preparações e gravação do NURC em Salvador. O PEPP surgiu da sugestão da professora Rosa Virgínia Mattos e Silva de que se implementassem estudos sobre os usos linguísticos na cidade do Salvador com a utilização de um novo acervo, o que mais adiante se iniciou. Foi com a professora Myrian Barbosa da Silva, contudo, que o PEPP ganhou forma, assumindo ela, então, a orientação de todas as etapas do programa, coordenado, na UNEB, por Norma da Silva Lopes, em projeto de Dedicação Exclusiva, e tendo Constância Maria Borges de Souza e Emília Helena Portella Monteiro de Souza, na época como doutorandas da Universidade Federal da Bahia, que passaram também a contribuir na constituição do corpus. O trabalho teve o apoio desde o início da Universidade do Estado da Bahia, através do Departamento de Ciências Humanas e da Pró-Reitoria de Pesquisa e Pós-Graduação. O trabalho de recolha da fala de Salvador foi até o final assumido pelas três professoras e se tornou objeto de observação e de estudo nas suas teses de Doutorado e de diversos outros estudos. 
Com o PEPP, pois, pretendeu-se, além de fornecer material de sincronia posterior à do NURC 70/SSA, suprir a falta de dados sobre o português falado pelos não universitários. O PEPP tem como níveis de escolaridade o Fundamental e o Médio (11 anos de estudo), daí o termo popular, por se saber que a massa popular representa a maior parte da população. Ao lado do PEPP, o NURC, hoje, já tem um acervo também mais atualizado, para cuja preparação também contribuiu o grupo que é responsável pela constituição do PEPP.

\section{O PEPP: FORMATAÇÃO E GRAVAÇÃO DAS ENTREVISTAS}

O PEPP é formado por quarenta e oito gravações de entrevista de aproximadamente quarenta minutos, com a seguinte caracterização: os informantes estão distribuídos em quatro faixas etárias: de 15 a 24 anos, de 25 a 35 anos, de 45 a 55 anos e de 65 anos em diante. Diante da precariedade de tempo na constituição da amostra, para não haver prejuízo na observação dos fatos a serem estudados, decidiu-se pela existência de um intervalo de dez anos entre as três últimas faixas do PEPP, que poderá, com a continuidade do trabalho e a ampliação das gravações, ser reduzido ou desfeito. A escolaridade dos informantes dessa amostra, como já foi dito, variou entre mínima, de 1 a 4 anos (pouca escolaridade), e máxima, de 11 anos de permanência na escola (média escolaridade).

\subsection{INFORMAÇÕES CADASTRAIS DOS INFORMANTES}

Na constituição do PEPP, foram de muita importância as informações catalogadas de cada informante. Foram tomadas informações, para a ficha cadastral: (i) do informante: nome, data e local de nascimento, bairros de nascimento e de morada posterior (duração), escolaridade (instituição de formação, se for o caso), profissão, local de trabalho e atividade que desenvolve, tipos de divertimento, bairros que frequenta, viagens feitas (duração e motivo), conhecimento de línguas estrangeiras (forma de aquisição); (ii) dos pais: nomes, bairros de nascimento e de morada posterior (duração), escolaridade e profissão, local de trabalho e atividade que desenvolve,; (iii) do companheiro(a) atual e/ou anterior, se for o caso: naturalidade, nível de escolaridade, profissão, atividade que desenvolve ou desenvolvia e a duração; (iv) do(s) filho(s), se tiver: prenome e escolaridade e ocupação de cada um; (v) de amigos mais próximos: idade, escolaridade e profissão; (vi) da relação inquiridor e informante: grau de intimidade entre os dois (nenhum conhecimento anterior, pouca ou muita intimidade).

\subsection{AS GRAVAÇÕES}

A escolha do local das gravações das entrevistas procurou atender sempre cada situação. Algumas gravações ocorreram na residência do entrevistado, ou no seu local de trabalho e outras na casa do inquiridor. Se a casa do entrevistado fosse a opção de local indicada por ele e permitisse a tranquilidade da gravação, sem o risco de interferências, 
esse seria o espaço escolhido. Cada caso foi estudado, e se buscou o que se considerou que levava a menos perdas. Procurou-se criar, para a recolha do material do PEPP, uma situação o mais próxima possível da coloquial, embora os informantes soubessem que iriam ser gravados. Foi dito a cada informante que o recurso da gravação se devia à impossibilidade de anotar e participar da conversa, ao mesmo tempo. Utilizou-se como tema a educação do passado e do presente, os castigos, a relação entre pais e filhos. $\mathrm{O}$ tema escolhido contribuiu bastante para o clima informal das conversas, pois falar do tempo de criança, de como os informantes foram tratados pelos pais, pelos primeiros professores, da educação dos filhos mostrou-se com o poder de quebrar o formalismo da situação e os indivíduos que, no início da entrevista, demonstraram se preocupar com o fato de estarem sendo gravados, ao falar desses assuntos, deram indícios de terem esquecido a gravação e ficaram aparentemente à vontade. Foi assim que até lágrimas surgiram nos olhos de muitos dos entrevistados quando lembraram de fatos de sua infância/adolescência. Apesar de constrangido, muitas vezes, por ter provocado a situação, o inquiridor se sentiu vitorioso por haver conseguido que o informante se "desarmasse" totalmente e assim se obtivesse uma amostra mais próxima do vernáculo, no sentido laboviano do termo. Na realização dos inquéritos, alguns procedimentos foram adotados com a finalidade de levar o informante a se comportar o mais naturalmente possível. Dessa maneira, procurou-se fazer contatos com o informante antes do dia da entrevista para que, no dia acertado, no mínimo o segundo momento, já se tivesse reduzido o grau de formalidade na relação entre o informante e o documentador responsável pelo trabalho.

$\mathrm{Na}$ entrevista, para garantir que a conversa seguisse o rumo previsto e se conseguisse atingir os objetivos propostos, foi elaborado um guia-questionário a ser aplicado. Como as pessoas inquiridas tinham idade e escolaridade diferentes, foram feitas adaptações ao guia-questionário, tentando atender a essas diferenças. Para os mais jovens, por exemplo, não se procurou inquirir sobre educação dos filhos, sobre a vida de antigamente. Além disso, não se procurou entrevistar os pouco escolarizados sobre muitas de suas vivências na prática escolar, senão quanto à possível vontade de estudar mais, impedimentos e os poucos contatos com a escola. Não houve, também, um compromisso de ser exaustivo no cumprimento dos questionamentos do guia, que funcionou realmente apenas como um instrumento para ter assunto para que a conversa fluísse.

Para as gravações, foram utilizados gravadores Lenox Sound AM/ FM Stereo Cassette Recorder, Modelo CT-731, posteriormente, cassettes BASF Ferro Extra, de 90 minutos de duração, visando a evitar que se obtivessem originais com interrupções. As cópias foram feitas em rádio gravador CCE, com fitas de marcas diversas, de sessenta minutos. Todo material coletado passou pela fase da validação. Após a coleta do material oral, foram ouvidas todas as fitas para que se procedesse à transcrição. Alguns inquéritos foram invalidados em função da baixa qualidade da gravação, inibição do informante, além de inquéritos com falas ininteligíveis. Alguns textos invalidados foram refeitos, outros foram substituídos por novas entrevistas. Em 2003 com recurso do Projeto Vertentes do Português Brasileiro: Acervos Linguísticos Urbanos de Salvador, coordenado por Norma Lopes, apresentado à FAPESB para concorrer à bolsa PRODOC 
/ FAPESB, foram adquiridos equipamentos e materiais necessários aos inquéritos para passar o PEPP para mídia digital. Para tanto, contou-se com a colaboração de bolsistas de Iniciação Científica.

Os textos das entrevistas foram transcritos, seguindo-se as normas definidas pelo Projeto NURC/Salvador. A transcrição do PEPP é grafemática, bastante próxima das normas ortográficas vigentes, inclusive quanto à pontuação. Embora não estejam representadas as características da oralidade, algumas peculiaridades fônicas como as formas contractas transcrevem-se da seguinte forma: pro(s), pra(s), prum, num, né, tá, dentre outras. Foram adotadas, também, as seguintes:

- as hesitações da fala, palavras truncadas são indicadas por reticências [...];

- as interrupções da fala de um dos locutores pelo outro são também indicadas por reticências;

- as superposições de falas são assinaladas com a abreviatura (superp);

- os risos durante ou após a elocução são indicados entre parênteses (risos);

- as citações e as reproduções do discurso direto são indicadas entre aspas;

- as datas e indicações numéricas são transcritas grafematicamente;

- as palavras de origem estrangeira figuram em itálico;

- os trechos ininteligíveis e inaudíveis são assinalados com a indicação (inint);

- as interrupções das gravações são marcadas com (interrup);

- os nomes próprios, exceto os de pessoas públicas, são identificados, apenas, por suas iniciais maiúsculas, visando à preservação de suas identidades;

- a identificação dos informantes em cada inquérito se faz pelo seu número de catalogação nos arquivos do PEPP.

Adotaram-se, para a seleção de informantes do PEPP, os mesmos critérios do Projeto NURC, a fim de tornar as amostras o mais intercomparáveis possível. Assim, a primeira exigência foi que eles fossem naturais de Salvador e, além disso, que tivessem permanecido nesta cidade a maior parte de suas vidas. Para excluir a interferência de outros dialetos, seus pais também deveriam ser de Salvador, ou que tivessem vindo para esta cidade ainda muito pequenos.

Além das informações referentes a dados de identificação, como idade, sexo e escolaridade, outras informações foram catalogadas em ficha para que, posteriormente, se pudesse estabelecer alguma relação entre esses dados e a fala do informante. Assim, a ficha cadastral registrou do entrevistado a sua residência, profissão, tipo de diversão, nível de escolaridade dos amigos mais próximos, viagens, contatos com línguas estrangeiras, idade de filhos, casamentos anteriores etc.

Da amostra PEPP, os informantes com pouca escolarização se situam mais em regiões periféricas: Tancredo Neves ( 5 pessoas), Mata Escura, Pernambués (3 pessoas), São Caetano, Itapagipe, Sussuarana (3 pessoas), Periperi e Simões Filho (região metropolitana) (2 pessoas). Esses locais se situam em pontos distantes, alguns deles tiveram crescimento demográfico bastante rápido nos últimos anos, muitos surgiram há poucos anos e são habitados principalmente por uma população de baixa renda. Apenas um informante mora na Barra, um no Tororó, outro na Vasco da Gama, bairros próximos ao centro da cidade. Parte dos que têm nível Médio residem também em bairros mais 
distantes do centro, a exemplo de Saboeiro, Plataforma, Paripe, Mussurunga, Massaranduba e Cabula VI. Mas muitos deles moram em bairros em que residem também pessoas de classe média; são bairros mais próximos do centro e, portanto, considerados bons lugares para morar. Entre eles, o Lanat, Baixa de Quintas, IAPI, e outros que, apesar de, na época de constituição do acervo, serem considerados mais distantes do centro (hoje não mais), concentram muitas pessoas de classe média. Há, também, alguns em bairros na época também habitados por pessoas de classe média/alta: Caminho das Árvores, Monte Serrat, Boca do Rio, Itapagipe. Os informantes têm ocupações diversas. Quanto às ocupações, entre os homens do primeiro nível de escolarização, 1 a 5 anos de contato com a escola, há dois alfaiates, um vendedor-representante (ex-gerente de empresa comercial), um contínuo, um encanador, um inspetor de alunos (de escola de curso médio), um lavador de carros, um porteiro, um responsável por serviços gerais e um vendedor de cafezinho. As mulheres com a mesma escolaridade têm as seguintes ocupações: duas desempregadas, uma ajudante de cozinha, quatro faxineiras de residências e uma de prédios, uma servente de escola, uma mãe de santo (dona de terreiro de candomblé) e uma escrevente de cartório aposentada. A maior parte dessas ocupações não são empregos formais, somente sete dos informantes (quatro homens e três mulheres) têm salário fixo, são empregados ou aposentados. Com o Ensino Médio completo há, entre os homens, as profissões: instrutor de informática, jogador de futebol, inspetor de alunos (que atua como auxiliar de disciplina), ex-controlador de voo aposentado, motorista, funcionário de escritório de supermercado, porteiro, estudante e contador autônomo (que faz serviços esporádicos). Entre as mulheres, há as ocupações: auxiliar de enfermagem, estudante, técnico em fotografia e locução free-lance, professora primária aposentada, estagiária, dona-de-casa, ou membro de grupo de $3^{\mathrm{a}}$ idade.

\section{O VALOR DO PEPP NO CONTEXTO BAIANO}

No estado da Bahia, o NURC foi por décadas praticamente o único acervo disponível para observação de fatos linguísticos, com a limitação de incluir apenas falantes com escolaridade superior. Estudos da fala popular (com escolaridades Fundamental e Média) iniciaram-se com o PEPP. Até o momento, diversas pesquisas de doutorado, de pós-doutorado, dissertações de mestrado, tomaram suas entrevistas como objeto de observação, além de artigos científicos, apresentações orais em eventos, capítulos de livros, além de trabalhos de conclusão de curso e pesquisas de Iniciação Científica, dentre outros trabalhos.

Particularmente na Universidade do Estado da Bahia, o PEPP, com o foco na fala popular, tem sido importante material em estudos variacionistas, em pesquisas sobre a sócio-história e mudança do português brasileiro, em estudos funcionalistas na linha da gramaticalização.

O PEPP tem possibilitado a ampliação da pesquisa sobre os usos linguísticos em Salvador, e na Bahia, com pesquisas nos diversos campi da UNEB e em outras instituições, contribuindo para o conhecimento do português brasileiro. Contribuiu para a formação dos estudantes de Letras, para uma atuação consciente como professor, e para a formação de pesquisador, com estudos em diversos níveis da língua. 
$\mathrm{Na}$ seção seguinte, listam-se algumas pesquisas científicas de fenômenos diversos do português com a observação do acervo de que trata o presente texto.

\section{PESQUISAS REALIZADAS COM O ACERVO DO PEPP}

Nesta seção citam-se pesquisas que tomaram o PEPP como corpus de pesquisa. Apresentam-se separados por níveis de pesquisa e tipo de publicação: teses de doutorado, dissertações de mestrado, pesquisas de cursos de especialização, de trabalhos de Iniciação Científica e de conclusão de curso de graduação. Além desses, há também um de pósdoutorado. Entre os trabalhos publicados, há livros, capítulos de livros e artigos. Neste artigo, apenas são apresentados resumos das teses; o mesmo não se faz para todos os outros trabalhos referidos.

\subsection{TESES DE DOUTORADO}

LOPES, Norma da Silva. Concordância nominal, estrutura linguística e sociedade. Salvador: UFBA, 2002. (Tese de Doutorado)

Esse trabalho faz uma análise da variação da concordância de número no sintagma nominal do português brasileiro, utilizando o acervo do Programa de Estudo do Português Popular de Salvador, o PEPP. A pesquisa toma como escopo teórico-metodológico a sociolinguística variacionista laboviana, que considera que a variação é inerente ao sistema, cabendo ao sociolinguista identificar as variáveis sociais e as linguísticas que estão relacionadas ao fenômeno variável em observação. Para entender o processo da variação, são também utilizados pressupostos de outros referenciais teóricos, tomados como auxiliares. A pesquisa identifica quatro variáveis linguísticas intimamente associadas à variação da concordância nos elementos do sintagma nominal: 1) a saliência fônica; 2) a classe gramatical, a posição linear e a relativa, associadas; 3) as marcas precedentes e 4) o contexto subsequente. Essas são as mesmas variáveis linguísticas que se mostram mais relacionadas ao fenômeno em outras regiões do País, evidenciando que as restrições existentes no processo da variação da concordância no sintagma nominal no português, como um todo, são as mesmas. Analisando os diversos grupos sociais que compõem a amostra, observa-se que três variáveis sociais têm mais relação com a variação da concordância: 1) a escolaridade, 2) a faixa etária e 3) a etnia, neste trabalho observada através dos sobrenomes dos informantes. Os resultados indicam que 1) a presença de concordância é proporcional ao tempo de relação com a atividade escolar; 2) os mais jovens do grupo de sobrenome religioso, grupo considerado de ancestralidade escrava, fazem mais concordância que os mais velhos, indicando tendência de aumento da realização de concordância; 3) os mais novos do grupo de sobrenome não religioso, grupo considerado de ancestralidade não escrava, tendem a realizar menos concordância que os mais velhos, indicando uma tendência de redução ou enfraquecimento da concordância. A diferença entre os resultados dos grupos de ancestralidade escrava e não escrava constitui evidência de que o português utilizado por descendentes da etnia negra, no Brasil, na sua fase inicial, foi caracterizado por pouca concordância, resultado de exposição a dados linguísticos primários mais variados e divergentes, condizente com o contexto social em que os negros estiveram envolvidos. Enquanto essa população, aos poucos, aproxima-se do padrão, por situação diversa passam as pessoas que não tiveram essa mesma história: cada vez mais reduzem a concordância dentro do sintagma nominal, ampliando o quadro da variação. O estudo realizado revela, pois, que há forças diferentes em concorrência no universo linguístico de Salvador, situação que se relaciona com o processo histórico em que essa cidade se envolveu na fase da constituição do seu povo e de sua língua. 
SOUZA, Emília Helena. A multifuncionalidade do ONDE na fala de Salvador. Salvador: UFBA, 2003. (Tese de Doutorado)

Esse trabalho é um estudo do ONDE na fala de Salvador. Como base teórica tomam-se os pressupostos do Sociofuncionalismo Linguístico na linha da Gramaticalização e da Sociolinguística Variacionista. Verifica-se o comportamento do ONDE, e se esse item está passando por um processo de Gramaticalização, e em que níveis. Parte-se da visão multissistêmica da língua, em que cada sistema é visto atuando em conjunto, podendo ser representado de uma forma radial, tendo o Léxico no meio e à volta o Discurso, a Semântica e a Gramática. Como procedimentos para a análise do ONDE foram constituídos grupos de fatores sociais e grupos de fatores linguísticos, esses últimos a partir dessa visão modular da língua, considerando-se o ONDE como um item gramatical, e portador de propriedades semânticas, discursivas e gramaticais, que são ativadas no evento da comunicação. Os valores do ONDE são tomados como o principal grupo de fatores, a partir do qual são observados os demais, os sociais, e os linguísticos. Analisaram-se gramáticas prescritivas e descritivas, também foi feito um estudo histórico-diacrônico da língua portuguesa e comparou-se com um estudo descritivo do où na língua francesa. Os corpora, base da análise, são constituídos do PEPP (Programa de Estudos do Português Popular de Salvador), em sua totalidade, e amostra do corpus NURC/SSA/90.

SOUZA, Constância. A concordância verbal na fala de Salvador: duas realidades sociolinguísticas. Salvador: UFBA, 2009. (Tese de Doutorado)

Esse estudo tem como objetivo geral analisar a relação entre a variação da concordância verbal e o processo de formação do português brasileiro. A concordância, tanto a verbal quanto a nominal, apesar de ser um fenômeno variável, é exigida socialmente e quem não segue a tradição é avaliado negativamente, devido à forte pressão escolar e exigência da sociedade dominante. Com base na sociolinguística variacionista, este trabalho busca explicações para a variação na concordância verbal no português falado em Salvador, analisando fatores linguísticos (internos à língua) e fatores sociais (externos à língua). Observando-se a interação desses fatores, verifica-se de que modo eles condicionam a presença ou ausência de marcas flexionais no verbo. Esta pesquisa toma como embasamento teórico a teoria da variação, segundo Labov $(1972,1982,1994)$, e o conceito de transmissão linguística irregular, postulado por Lucchesi $(2000,2001)$, além de outros trabalhos de abordagem sociolinguística. Com o estudo do fenômeno da variação da concordância verbal na fala popular de Salvador, constata-se que o português brasileiro foi formado no cenário de uma realidade linguística bipolarizada, tendo, de um lado, a norma culta e, de outro, a norma popular ou vernácula (LUCCHESI, 2001, 2002). Neste estudo, analisou-se uma amostra constituída de inquéritos extraídos do Programa de Estudos do Português Popular Falado em Salvador (PEPP/SSA) e inquéritos extraídos do Programa Norma Urbana Culta de Salvador (NURC). A concordância verbal é uma regra variável com grande ausência de marcas na fala popular, sendo marcada pelos falantes cultos em razão da pressão escolar e exigência do mercado ocupacional.

\section{ROCHA, Eva. Apagamento de preposições em fronteiras sentenciais completivas e relativas no} português. Salvador: UFBA, 2009. (Tese de Doutorado)

Tomando como base teórica a Teoria da Variação laboviana, descreve-se o apagamento de preposições diante de que em fronteiras sentenciais completivas e relativas finitas na língua portuguesa falada do Brasil e de Portugal, em amostras constituídas em duas sincronias (década de 70 e década de 90 do século XX), num estudo de tendência, em tempo real de curta duração. Partindo-se da hipótese de que o português brasileiro passa por um processo de mudança linguística no tocante ao uso de preposições, e que esta é uma característica da língua portuguesa atual, na sua dimensão geográfica, objetiva-se identificar os condicionamentos linguísticos e extralinguísticos para a implementação do fenômeno em cada região, assim como indícios de mudança. Os dados foram retirados de amostras de fala culta (de indivíduos com nível universitário - mínimo de 15 anos de escolarização) de Salvador, do Rio de Janeiro, e de Portugal, e de 
falantes de Salvador, com diferentes níveis de escolarização (de 4 a 11 anos de escolarização), utilizando entrevistas do Programa de Estudos sobre o Português Popular de Salvador, o PEPP. Foram consideradas inicialmente três variantes na variável dependente para as orações completivas (presença canônica da preposição; apagamento da preposição; inserção não canônica da preposição) e quatro, para as orações relativas: presença canônica da preposição, apagamento da preposição, inserção não canônica da preposição, troca de preposição; embora a análise dos dados tenha sido binária, considerando-se apenas as duas variantes mais produtivas: presença canônica e o apagamento da preposição. Constatou-se que o apagamento da preposição é a variante mais usada, tanto em orações completivas quanto em orações relativas, espelhando, no entanto, duas realidades sociolinguísticas distintas: variação estável, nas orações completivas, e mudança linguística em curso, nas orações relativas. Nas orações completivas, o nível de escolaridade do falante, o tipo de oração e a região condicionam o apagamento, enquanto nas orações relativas o tipo de preposição, o gênero/sexo do falante e a região são responsáveis pela implementação da variante apagamento no português brasileiro. Na amostra do português europeu, há uma realidade oposta, ocorrendo a predominância da variante canônica, nas orações relativas.

\subsection{DISSERTAÇÕES DE MESTRADO}

LUZ, Cláudia Norete Novais. Velejando sobre as águas da retomada anafórica do objeto direto: um cruzeiro na fala em Salvador. Salvador: PPGEL/UNEB, 2009.

SANTANA, Abdon Mendes Borges. Nós e A gente: um retrato do português popular de Salvador: PPGEL/UNEB, 2014

CARVALHO, Valter. Você, a gente et alia indeterminam o sujeito em Salvador. Salvador: PPGEL/UNEB, 2010. (Dissertação de mestrado)

FERREIRA, Naiara de Souza. O fenômeno de redução da partícula não no português falado na cidade de Salvador. PPGEL/UNEB, 2014.

\subsection{PESQUISA DE PÓS-DOUTORADO}

ROCHA, Eva Neri. A variação na expressão dos particípios na escrita e na fala em Salvador. Salvador: PPGEL/UNEB, 2016 (Relatório de Pós-Doutorado)

\subsection{PESQUISAS DE IC}

ALMEIDA, Rafael Soares. Programa de Estudos sobre o Português Popular de Salvador, PEPP: ampliação do acervo e descrição linguística. Salvador: FAPESB/UNEB, 2006. (Pesquisa de Iniciação Científica)

NASCIMENTO, Caroline Reis. Estudos da variação em Salvador. Salvador: UNEB, 2005. (Pesquisa de Iniciação Científica)

BATISTA, Marli Pereira. O uso do aumentativo e do diminutivo em Salvador. Salvador: FAPESB/UNEB, 2012. (Pesquisa de Iniciação Científica)

NASCIMENTO, Lorena Cristina Ribeiro. A variação Ter/haver em Salvador. Salvador: FAPESB/UNEB, 2012. (Pesquisa de Iniciação Científica) 
SILVA, Viviane Marcelina da. A variação no uso do futuro em Salvador. Salvador: FAPESB/UNEB, 2012. (Pesquisa de Iniciação Científica)

SILVA, Viviane Marcelina da. O uso das formas nominais de indeterminação em Salvador. Salvador: FAPESB/UNEB, 2013. (Pesquisa de Iniciação Científica)

NASCIMENTO, Lorena Cristina Ribeiro. A variação no uso do modo subjuntivo em Salvador. Salvador: FAPESB/UNEB, 2013. (Pesquisa de Iniciação Científica)

SOUZA, Carlos César Borges Nunes de. Estratégias de relativização na fala popular de Salvador. Salvador: FAPESB/UNEB, 2015. (Pesquisa de Iniciação Científica)

SOUZA, Carlos César Borges Nunes de. O item QUE em Salvador: um estudo sócio-funcionalista. Salvador: CNPQ/UNEB, 2014. (Pesquisa de Iniciação Científica)

ROCHA, Taíse. Variação nos usos dos particípios em Salvador. Salvador: PICIN/UNEB, 2015. (Pesquisa de Iniciação Científica)

DE DEUS, Rebeca Lorena Carrilho Magalhães. Variação na regência de verbos de movimento na fala de Salvador. Salvador: PICIN/UNEB, 2016. (Pesquisa de Iniciação Científica)

BOMFIM, Caroline Pereira. A variação da preposição EM/NI na fala de Salvador. Salvador: PICIN/UNEB, 2016. (Pesquisa de Iniciação Científica)

SANTOS, Leidiclécia Oliveira. Gramaticalização de verbos e o contexto morfossintático de primeira pessoa do plural. 2016. Iniciação Científica. (Graduando em Letras - Língua Portuguesa) - Universidade do Estado da Bahia, Conselho Nacional de Desenvolvimento Científico e Tecnológico. Orientador: Cristina dos Santos Carvalho.

RAMOS, Micaelle Oliveira. Usos (não) gramaticalizados do verbo ESPERAR na fala popular de Salvador. 2016. Iniciação Científica. (Graduando em Letras - Língua Portuguesa) - Universidade do Estado da Bahia, Conselho Nacional de Desenvolvimento Científico e Tecnológico. Orientador: Cristina dos Santos Carvalho.

\subsection{TRABALHOS DE CONCLUSÃO DE CURSO}

SOUZA, Carlos César Nunes de. A estratégia relativa cortadora na fala popular e culta em Salvador: mudança em andamento? Salvador: UNEB, 2016. (Trabalho de conclusão de curso)

SAMPAIO, Sirlene. Monotongação nos ditongos (ay) e (ey) em posição medial no português brasileiro. Salvador: UNEB, 2016. (Trabalho de conclusão de curso)

NASCIMENTO, Lorena Cristina Ribeiro. A variação do subjuntivo na fala popular de Salvador: condicionamento estrutural e social. Salvador: UNEB, 2013 (Trabalho de conclusão de curso)

SILVA, Viviane Marcelina da. As formas de indeterminação do sujeito na fala de Salvador. Salvador: UNEB, 2013 (Trabalho de conclusão de curso)

OLIVEIRA, Ana Márcia Santos de; JESUS, Hilária Souza de. A concordância verbal em estruturas com o pronome SE apassivador. Salvador: Faculdade Jorge Amado, 2006. (Trabalho de conclusão de curso)

SOUSA, Luís Cláudio da Hora; SANTOS, Maria da Paixão Dias. A variação de SEU e DELE na mídia. Salvador: Faculdade Jorge Amado, 2006. (Trabalho de conclusão de curso)

SILVA, Cristiane Lima da; SIRQUEIRA, Aline Naegel. A variação na posição do adjetivo na língua falada em Salvador. Salvador: Faculdade Jorge Amado, 2006. (Trabalho de conclusão de curso) 
CARNEIRO, Kátia Paloma F. ; PORTELA, Manuela Lima. O uso do diminutivo em Salvador. Salvador: Faculdade Jorge Amado, 2006. (Trabalho de conclusão de curso)

ARAÚJO, Michelle Cristine G. de; NASCIMENTO, Naiara S. do. O uso dos pronomes SEU e DELE: ambiguidades provocadas pelo pronome SEU. Salvador: Faculdade Jorge Amado, 2006.

(Trabalho de conclusão de curso)

CONCEIÇÃO, Caroline da Silva; SILVA, Gilselma Cedraz da. Clíticos na língua falada do povo soteropolitano. Salvador: Faculdade Jorge Amado, 2006. (Trabalho de conclusão de curso)

LUZ, Cláudia Norete Novais, Realização estratégica do objeto direto anafórico na fala dos soteropolitanos. Salvador: Faculdade Jorge Amado, 2006. (Trabalho de conclusão de curso)

CERQUEIRA, Ivana Conceição de Freitas. Ter e Haver na fala de Salvador. Salvador: Faculdade Jorge Amado, 2006. (Trabalho de conclusão de curso)

LEAL, Janúzia Silva do Espírito Santo. A regência do verbo IR de movimento na fala de Salvador. Salvador: Faculdade Jorge Amado, 2005. (Trabalho de conclusão de curso)

SILVA, Neuza Alves. O uso do diminutivo na fala de Salvador. Salvador: Faculdade Jorge Amado, 2005. (Trabalho de conclusão de curso)

JESUS, Emília Tatiane O. de; ASSIS, Silvane Gracielle C. de. O uso do futuro simples e do perifrástico na língua falada. Salvador: Faculdade Jorge Amado, 2005. (Trabalho de conclusão de curso)

SILVA, Helenice M.; PESTANA, Gilvandro. Ter/Haver nas falas popular e universitária em Salvador. Salvador: Faculdade Jorge Amado, 2005. (Trabalho de conclusão de curso)

TEODORO, Aliane Pereira Alves. A Gente / Nós no Português de Salvador. Salvador: Faculdade Jorge Amado, 2004. (Trabalho de conclusão de curso)

SANTOS, Magda; SOUZA, Cleide; NEVES, Elcicleide. Ter de e Ter que na fala de Salvador. Salvador: Faculdade Jorge Amado, 2004. (Trabalho de conclusão de curso)

DIAS, Valter de Carvalho. Você, Pronome Indeterminado. Salvador: Faculdade Jorge Amado, 2004. (Trabalho de conclusão de curso)

OLIVEIRA, Tânia dos Santos de. A variação linguistica do português. Salvador: Faculdade Jorge Amado, 2003. (Trabalho de conclusão de curso)

GOMES, Jande Cleia Capistrano. Gramaticalização do verbo OLHAR na fala popular de Salvador. Salvador: UNEB, 2015. (Trabalho de Conclusão de Curso) Orientador: Cristina dos Santos Carvalho.

PIMENTEL, Emily Karoline Oliveira. Gramaticalização das construções DIZ QUE e DISSE QUE na fala popular de Salvador. 2015. Trabalho de Conclusão de Curso. (Graduação em Letras - Língua Portuguesa) - Universidade do Estado da Bahia. Orientador: Cristina dos Santos Carvalho.

MASCARENHAS, Camila Carneiro. Estratégias de indeterminação na fala popular urbana de Salvador e na fala rural do povoado de Maracujá: uma análise variacionista. 2012. Trabalho de Conclusão de Curso. (Graduação em Letras Vernáculas) - Universidade do Estado da Bahia. Orientador: Cristina dos Santos Carvalho.

SILVA, Rosana Cristina Lima da. Estratégias de relativização na fala popular de Salvador: uma análise sociolinguística. 2012. Trabalho de Conclusão de Curso. (Graduação em Letras Vernáculas) - Universidade do Estado da Bahia. Orientador: Cristina dos Santos Carvalho.

SILVA, Eliêda de Matos. Gramaticalização do verbo achar na fala popular de Salvador. 2012. Trabalho de Conclusão de Curso. (Graduação em Letras Vernáculas) - Universidade do Estado da Bahia, Fundação de Amparo à Pesquisa do Estado da Bahia. Orientador: Cristina dos Santos Carvalho 


\subsection{MONOGRAFIAS DE ESPECIALIZAÇÃO}

SILVA, Eliêda de Matos. Quer Dizer: indícios de gramaticalização na fala popular de Salvador. Salvador: UNEB, 2014. Monografia. (Aperfeiçoamento/Especialização em Especialização em Linguística)

MOTA, José Reinan Moreira. Gramaticalização de VER: uma análise funcionalista da fala soteropolitana. 2014. Monografia. (Aperfeiçoamento/Especialização em Especialização em Linguística)

\subsection{LIVROS}

LOPES, Norma da Silva; SOUZA, Constância; SOUZA, Emília Helena. (Organizadoras). Um estudo da fala popular de Salvador: PEPP. Salvador: Quarteto, 2009.

LOPES, Norma da Silva. A fala baiana em destaque: a concordância nominal no português de Salvador. Munchen: Peniope, 2011.

\subsection{CAPÍTULOS DE LIVROS}

LOPES, Norma. O PEPP: histórico e caracterização. In: LOPES, Norma da Silva; SOUZA, Constância; SOUZA, Emília Helena. (Organizadoras). Um estudo da fala popular de Salvador: PEPP. Salvador: Quarteto, 2009.

LOPES, Norma. A concordância nominal nos falantes de Salvador. In: LOPES, Norma da Silva; SOUZA, Constância; SOUZA, Emília Helena. (Organizadoras). Um estudo da fala popular de Salvador: PEPP. Salvador: Quarteto, 2009.

LOPES, Norma. Uma ou duas gramáticas no português brasileiro? In: LOPES, Norma. Tópicos em variação do português. Curitiba, Appris, 2012

SOUZA, Constância. A concordância verbal em Salvador: resultado de transmissão linguística irregular? In: LOPES, Norma da Silva; SOUZA, Constância; SOUZA, Emília Helena. (Organizadoras). Um estudo da fala popular de Salvador: PEPP. Salvador: Quarteto, 2009.

SOUZA, Emília Helena. Os valores do onde em contextos de língua falada. In: LOPES, Norma; SOUZA, Constância; SOUZA, Emília Helena. (Organizadoras). Um estudo da fala popular de Salvador: PEPP. Salvador: Quarteto, 2009.

LUZ, Cláudia Norete. Navegando em realização estratégica do objeto direto anafórico na fala dos soteropolitanos. In: LOPES, Norma. Tópicos em variação do português. Curitiba, Appris, 2012.

SOUZA, Constância. A atuação das variáveis linguísticas na concordância verbal do português falado em Salvador. In: LOPES, Norma. Tópicos em variação do português. Curitiba, Appris, 2012.

ROCHA, Eva. Apagamento de preposições em orações completivas e relativas em Salvador. In: LOPES, Norma. Tópicos em variação do português. Curitiba, Appris, 2012

DIAS, Valter de Carvalho. Marcas de indeterminação na fala urbana de Salvador. In: LOPES, Norma. Tópicos em variação do português. Curitiba, Appris, 2012. 
LOPES, Norma. As bases do português popular de Salvador. In: LOPES, Norma; SOBRAL, Gilberto; OLIVEIRA, Jaciara. Linguagem na cidade: estudos sócio-discursivos. Salvador: Quarteto, 2012. (FAPESB)

LOPES, Norma; NASCIMENTO, Lorena; BATISTA, Marli, SILVA, Viviane. Três fenômenos variáveis no português de Salvador. In: LOPES, Norma; SOBRAL, Gilberto; OLIVEIRA, Jaciara. Linguagem na cidade: estudos sócio-discursivos. Salvador: Quarteto, 2012. (FAPESB)

LUZ, Cláudia; LOPES, Norma. Embarcando nas ondas da retomada anafórica. In: LOPES, Norma; BULHÕES, Lígia; CARVALHO, Cristina. Sociolinguística: estudos... Feira de Santana: UEFS, 2013. (Projeto de pesquisa Linguagem na cidade: uma fotografia sócio-discursiva de Salvador.

FAPESB/PPGEL/UNEB)

LOPES, Norma. O que é que a baiana quem? Uma abordagem do gênero na concordância nominal. In: LOPES, Norma; BULHÕES, Lígia; PARCERO, Lúcia Maria. Salvador, sob o olhar da sociolinguística. Feira de Santana: UEFS, 2013. (Projeto de pesquisa Linguagem na cidade: uma fotografia sócio-discursiva de Salvador. FAPESB/PPGEL/UNEB)

SOUZA, Constância. Efeitos da escolaridade na concordância verbal do português falado em Salvador. In: LOPES, Norma; BULHÕES, Lígia; PARCERO, Lúcia Maria. Salvador, sob o olhar da sociolinguística. Feira de Santana: UEFS, 2013. (Projeto de pesquisa Linguagem na cidade: uma fotografia sócio-discursiva de Salvador. FAPESB/PPGEL/UNEB)

CARVALHO, Valter. A indeterminação do sujeito. In: LOPES, Norma; BULHÕES, Lígia; PARCERO, Lúcia Maria. Salvador, sob o olhar da sociolinguística. Feira de Santana: UEFS, 2013. (Projeto de pesquisa Linguagem na cidade: uma fotografia sócio-discursiva de Salvador. FAPESB/PPGEL/UNEB)

CARVALHO, Cristina; FERREIRA, Naiara. O fenômeno da redução da partícula NÃO no português falado soteropolitano: a gramaticalização em foco. In: LOPES, Norma; SOBRAL, Gilberto. A Bahia em perspectivas diversas. Salvador: Quarteto, 2015.

LOPES, Norma. Variação de gênero e número no português: uma explicação com base na teoria dos 4M. In: CARVALHO, Cristina; ROCHA, Flávia; PARCERO, Lúcia. Discurso e gramática: diálogos interdisciplinares. Salvador: EDUNEB, 2011.

LOPES, Norma. Variação e mudança: o mesmo fenômeno em fases distintas? In: Salvador em preto e branco: estudos do discurso, estudos sociolinguísticos.

NASCIMENTO, Lorena; LOPES, Norma. A variação do subjuntivo na fala popular de Salvador. Anais do III Encontro de Sociolinguística. Feira de Santana: UEFS, 2013

SILVA, Viviane; LOPES, Viviane. As formas de indeterminação do sujeito na fala de Salvador. Anais do III Encontro de Sociolinguística. Feira de Santana: UEFS, 2013

\subsection{Artigos}

LOPES, Norma da Silva. O mecanismo da variação da concordância no português: observações quanto a marcas nos verbos e nos nomes. Estudos da língua(gem). Ano 2015. v.13, p. 59-72. ISSN 1982-0534.

LOPES, Norma da Silva. Aquisição da concordância no português: uma explicação com base na teoria do 4M. Papia. V, 15, p. 72-79. ISSN 0103-9415

LOPES, Norma da Silva. Perda ou aquisição no português brasileiro? Papia. v. 13, p. 150-156, 2003.

LOPES, Norma da Silva. Variação ou mudança na concordância nominal em Salvador? Revista Estudos. 1999. ISSN 0102-5465 
ALVES, Jeferson da Silva. O objeto direto anafórico: uma análise na língua falada popular de jovens soteropolitanos. Revista Eletrônica de Divulgação Científica em Língua Portuguesa, Linguística e Literatura. Ano 05 n.11 - 2o Semestre de 2009- ISSN 1807-5193

Sobre a lista apresentada, é necessário informar que ela não é completa: faltam trabalhos resultados de pesquisas orientados em programa de Iniciação Científica, por colegas diversos do grupo de pesquisa, o Grupo Fala e Contexto no Português Brasileiro, o GconPort, por outros pesquisadores da UNEB em outros campi, dos quais não temos registro, e por orientandos de orientandos, difíceis de menção nesse momento. Não foram incluídas apresentações em forma de painéis, posters, comunicações, mesas-redondas, palestras, conferências.

\section{A PROPOSTA DO PEPP 2}

A seguir, apresentam-se as novas idéias que fundamentam a constituição do acervo em planejamento, o PEPP 2.

Planeja-se que se incluam informantes com escolaridade fundamental não só até a $5^{a}$. série, mas até a nona série. Dessa forma passarão a existir três níveis de escolaridade: Fundamental $1\left(1^{\circ}\right.$ a $5^{\circ}$ ano), Fundamental 2 (de $6^{\circ}$ ao $9^{\circ}$ ano) e nível Médio (até a $3^{\mathrm{a}}$ série desse nível), conservando-se as mesmas faixas etárias, para permitir o confronto entre elas nas duas sincronias.

O PEPP 2, na sua preparação, já planeja ampliar os itens que deverão constar na ficha cadastral dos informantes (v. em 6.1), diante da necessidade de adequar as questões aos novos costumes da era digital. Também deverão ser acrescentados novos temas de conversação que suscitem a fala sobre amigos, grupos, atividades diversas, para a obtenção de informações relativas a comunidades, grupos que os informantes frequentam e objetivos e características desses grupos. A seguir, em 6.1 apresentam-se novas informações cadastrais a serem preenchidas pelo pesquisador sobre cada informante do PEPP 2.

\subsection{NOVOS DADOS CADASTRAIS}

Além dos dados sobre os informantes já constantes na ficha cadastral do PEPP 1, serão incluídos o seguintes itens nos dados cadastrais de cada informante do PEPP 2, de forma a ter informações mais detalhadas sobre eles: 
(1) Tem celular, qual o uso? ( ) Como telefone apenas ( ) telefone e whatsapp ou

( ) outro uso também - dizer qual

(2) No whatsapp, ( ) fala só ( ) escreve só ( ) fala e escreve?

(3) Usa facebook? ( ) Sim; ( ) Não. Faz parte de grupos? ( ) $\operatorname{sim}($ ) não

Tipos de grupo: De ( ) interesses comuns; ( ) de família; ( ) de trabalho

( ) de religião - dizer qual

Caso use, com que frequência? Quantos amigos, aproximadamente?

Outra rede social? Qual/is?

(4) Ouve rádio? ( ) AM? ( ) FM? ( ) Emissora de preferência?

Programas de preferência?

Quanto tempo por dia?

(5) Assiste a TV? ___ Emissora de preferência? Qual/Quais?

Programas de preferência? Cite quais ___ Quanto tempo por dia?

(6) Usa a internet? ( ) Não; ( ) Sim, pouco; ( ) Muito

Tem email? ___ Usa? ___ Recebe e-mails? ___ Em média, quantos por dia?

Envia e-mails? ( ) Em média, quantos por dia? ( )

Seus e-mails são predominantemente de $($ ) trabalho ou de $($ ) amigo?

Pesquisa na internet? ( ) Muito; ( ) Pouco ( ) Não

Tipo de pesquisa

Outro uso da internet

(7) Lê jornais ou revistas? Com que frequência?

( ) Nunca; ( ) Todos os dias; ( ) nos fins de semana; ( ) um dia ou outro

(8) Frequenta cultos religiosos? Sim ( ) Não ( ) Com que frequência?

Uma vez na semana( ) Uma vez no mês ( ) Outra

Participa de reuniões de grupos religiosos? Sim ( ) Não ( ) Com que frequência?

Uma vez na semana ( ); Uma vez no mês ( ) Outra

(9) Lê livros específicos da sua religião? Sim ( ) Não ( ) Com que frequência?

Todo dia ( ); Uma vez na semana ( ); Uma vez no mês ( ); Outra

Com essas informações a serem solicitadas na ficha cadastral do informante e com a exploração de temas sobre a vida em grupo do entrevistado, informada no preenchimento da ficha, a conversa pode dar uma boa contribuição sobre a vida e a inserção social dessas pessoas. Esses dados são de fundamental importância para os estudos futuros a serem realizados com a observação desse novo acervo.

\section{CONSIDERAÇÕES FINAIS}

Este texto apresentou dados do PEPP, acervo da fala popular de Salvador, seus objetivos, características e sua importância para os estudos linguísticos na Bahia. Ao lado do NURC, com o estudo da fala universitária em Salvador, o PEPP tem sido observado em larga escala em estudos da fala popular de Salvador. Pode-se observar que a quantidade de estudos em nível de Iniciação Científica, em trabalhos de conclusão de curso é considerável. Além de estudos nesses dois níveis, algumas pesquisas de mestrado, de doutorado e de pós-doutorado tomaram esse acervo como corpus de observação. Dois livros constam da lista de produções com base no PEPP, e o número de capítulos de livros e artigos já publicados que partem da observação desse mesmo material revela a importância do PEPP na pesquisa lingüística baiana.

O PEPP 2 (novo acervo do português não universitário de Salvador) está em programação. Neste texto, apresentaram-se idéias iniciais, em forma de ampliação do 
número de escolaridades, acréscimo de informações na ficha cadastral dos informantes e também no guia-questionário.

\section{REFERÊNCIAS}

ECKERT, P. Three waves of variation study: the emergence of meaning in the study of sociolinguistic variation. Annual Review of Anthropology, Palo Alto, n.41, p.87-100, 2012.

FREITAG, Raquel Meister Ko. Bancos de dados sociolinguísticos do português brasileiro e os estudos de terceira onda: potencialidades e limitações. Alfa, São Paulo, 56 (3): 917944, 2012.

GUY, Gregory. A identidade linguística da comunidade de fala: paralelismo interdialetal nos padrões de variação linguística. Organon. v. 14, n. 28-29, p. 1-2, (2000). Acesso em 4/11/2017.

LABOV, William. Padrões sociolinguísticos. Trad. de Marcos Bagno, Maria Marta Pereira Scherre e Caroline R. Cardoso. São Paulo: Parábola Editorial, 2008.

LOPES, Norma; SOUZA, Constância; SOUZA, Emília Helena. A fala popular de Salvador: PEPP. Salvador: Quarteto, 2009.

Recebido em: 28/12/2017

Aprovado em: 26/01/2018

Publicado em: 01/03/2018 